\section{Pesquisa Qualitativa em Saúde e a Medicina Centrada no Paciente}

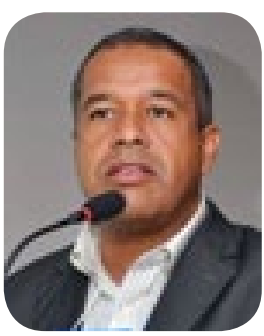

Ao longo do tempo, a pesquisa científica tem a do a base para o exercicio profissional na área de saúde. Metodologias sistematizadas, guidelines baseados em artigos científicos, medicina baseada em evidência e outras iniciativas sedimentaram medicina tecnológica, cujas praticas centradas no conhecimento técnico-cientifico ainda são o modelo prevalente nos dias atuais. Ocorre que, em recentes anos, a maioria dos pesquisadores concordam que ste modelo não salistaz plenamente os anse médico e pacientes. Exames em excesso, custo da ecnologia e afastamento nas relações humanas com os pacientes são os principais problemas. Iniciativas atuais, tais como o chamado "choosing wisely"1, vêm entando retomar o conceito de medicina centrada no paciente, reconhecendo a individualidade do tratamento e questôes como necessidade de contempla a perspectiva subjetiva de cada pessoa. Neste editorial, vamos focar no importante papel da pesquisa qualitativa e semiquantitativa em saúde, na tentativa de olhar os procedimentos médicos sob a otica do paciente e nâo dos profissionais da area de saúde.

grande avanço tecnologico na área de saúde em contribuído sobremaneira com o gerenciamento do diagnóstico e da terapêutica. Ressonância magnética, ecocardiografia, PET-Scan, dentre centenas de exames e procedimentos, são indispensáveis às boas práticas medicas e, de certa maneira êm conduzido o pensamento clínico na tomada de decisões. A objetividade dos dados obtidos por tais avaliações permite indicar com muita certeza alterações de ordem anatômica e fisiopatológica. Avaliações clínicas baseadas na objetividade tecnológica também são essenciais para a análise dos resultados terapêuticos das intervenções médicas. Cada vez mais dependemos da tecnologia e das metodologias que quantificam, classificam ou demonstram alteraçoes invisiveis ao mais experiente dos clínicos.
Marcos Almeida Matos

A dependência de exames complementares e de guias de condutas clínicas baseadas em métodos obetivos e quantitativos tem afastado os profissionais de tambem da visão de que o tratamento deve também evar em consideração aspectos subjetivos específicos para cada individuo. As avaliaçôes clínicas baseadas em modelos quantitativos sem dúvida são fundamentais, mas, ainda assim, são incapazes de evidenciar 0 real impacto dos procedimentos na vida dos pacientes. Um tratamento objetivamente bem-sucedido, baseado aos individuos a satisfação esperada. Isto significa que muitos procedimentos clinicamente corretos, de acordem produzir resultados negativos sob a perspectiva

A diferença entre avaliações clínicas subjetivas e objetivas explicaria o motivo pelo qual pessoas tem cado cada vez mais insatisfeitas com procedimentos médicos tidos como adequados. Na avaliação subjetiva, são levados em conta as expectativas individuais e os impactos reais das terapêuticas na vida dos sujeitos. Aqui não importa se o procedimento é de últim geração ou baseado em evidências científicas de níve l, ou ainda se seus resultados são anatomicamente e fisiologicamente excelentes. O importante e saber o que o indivíduo submetido a tal tratamento sente, pensa, espera, deseja ou sofre em consequência do procedimento.

Instrumentos de medida qualitativos são capazes de detectar se terapêuticas clínicas adequadas geraram felicidade, satisfação ou mesmo melhor qualidade de vida ao paciente. Ou exatamente o contrário, se tais terapêuticas, ainda que recomendáveis universalmente, geraram infelicidade, insatisfação, mostrando-se desastrosas para a qualidade de vida. Este é o caso, por exemplo, de pacientes que se submetem a artroplatias e continuam insatisfeitos com os resultados ou saúde não só da relação humana com o paciente, mas nas melhores evidencias clínicas, pode não oferecer do com modernos guidelines, são desastrosos e poindividual dos sujeitos tratados. de ressecções neoplásicas que aumentam o sofrimendo paciente sem trazer qualidade de vida ou aumeno de sobrevida ${ }^{2}$.

As metodologias clínicas subjetivas, entretanto, também podem e devem ser quantificadas para serem palatáveis e adequadas ao cartesianismo do profissional da saúde, acostumado desde a faculdade a medidas quantitativas numéricas. Desta forma, avaliações subjetivas, tais como qualidade de vida relacionada à saúde, limitações de vida diária ou impactos de tratamentos, devem ser avaliadas por metodologias e instrumentos semiquantitativos ou quantitativos. Devem ornecer medidas de valores classificáveis numericamente como melhores ou piores, ainda que necessariamente não precisassem ser assim.

Muitos profissionais poderiam alegar falha na acurácia de instrumentos que medem a subjetividade. Como garantir que realmente existe uma medida de satisfação a um tratamento; o que significaria qualidade de vida relacionada à saúde baseada em questionários. Ocorre que muitos esquecem que mesmo os instrumentos puramente quantitativos trabalham com probabilidade e não com certezas. Por exemplo, dislipidemia significaria uma doença verdadeira ou uma probabilidade de adoecer; também não é possível saber com certeza se uma dosagem de glicose acima do normal significaria certeza de diabetes. A probabilidade é tanto maior quanto mais intensa for a medida tanto para métodos objetivos quanto subjetivos.

Nas medidas clínicas objetivas, chamamos de acurácia a capacidade de diferenciar doentes de não doentes, baseados na sensibilidade e especificidade da avaliação. Nas medidas subjetivas, a acurácia e substituida pela validade ${ }^{\lrcorner}$. Quanto maior a probabilidade da validade e da acurácia, maior a chance de que a variável medida esteja correta. Para que se tenha uma idela, a acuracia da ressonanncia magnética na identificação da hernia discal está em torno de $60 \%{ }^{4}$. Mesmo assim, aceitamos corriqueiramente este exame como "padraão-ouro" para o diagnóstico. Talvez tenhamos, entretanto, dificuldades em aceitar que uma avaliação da qualidade de vida medida como $20 \%$ pelo questionário WOMAC possa realmente indicar grave sofrimento neste mesmo hipotético paciente com hérnia discal.

se agora imaginarmos um paciente com excelente qualidade de vida e com doença intestinal inflamatória associada a polipose intestinal? Seria interessante pensar que este novo dado fosse capaz também de direcionar o procedimento terapeutico. Esta nova perspectiva nos obriga a debruçar sobre cada caso bus- cando o que é melhor a partir da ótica do paciente. Teremos que incorporar novas metodologias subjetvas às antigas e importantíssimas medidas clínicas objetivas. Teremos que individualizar e humanizar cada tratamento. $E$, fundamentalmente, teremos que decidir m conjunto com nossos pacientes.

\section{REFERÊNCIAS}

1. Salloch S, Ritter P, Wascher S, Vollmann J, Schildmann J. Medical Expertise and Patient Involvement A Multiperspective Qualitative Observation Study of the Patient's Role in Oncological Decision Making. Oncologist 19:654-660, 2014

2. Borásio GD, Jox RF. Choosing wisely at the end of life: the crucial role of medical indication. Swiss Med kly 146:w14369, 2016

3. Morley S, Snaith P. Principles of Psychological Assessment. In: Freeman C, Tyrer P (eds.) Research Methods in Psychiatry, Gaskell, London, 1989.

4. Matos MA, Gusmão MS. Diagnostic significance magnetic resonance in low back pain. Rev Salud $P$ blica 10:105-12, 2008.

1- Serviço de Ortopedia do HSI

Endereço para correspondência: marcos.almeida@hotmail.com 